\title{
OPEN Author Correction: Important At- Sea Areas of Colonial Breeding Marine Predators on the Southern Patagonian Shelf
}

\author{
Alastair M. M. Baylis $\mathbb{D}^{\mathrm{D}}$, Megan Tierney, Rachael A. Orben, Victoria Warwick-Evans, \\ Ewan Wakefield, W. James Grecian, Phil Trathan, Ryan Reisinger $\mathbb{D}^{\mathbb{B}}$, Norman Ratcliffe, \\ John Croxall, Letizia Campioni, Paulo Catry, Sarah Crofts, P. Dee Boersma, Filippo Galimberti,

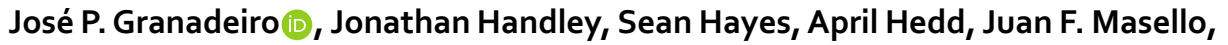 \\ William A. Montevecchi, Klemens Pütz $\mathbb{D}$, Petra Quillfeldt, Ginger A. Rebstock, \\ Simona Sanvito, lain J. Staniland \& Paul Brickle
}

Correction to: Scientific Reports https://doi.org/10.1038/s41598-019-44695-1, published online 11 June 2019

The original version of this Article contained an error in the name of the author José P. Granadeiro, which was incorrectly given as Jose Granadeiro.

In the original version of this Article, Ginger A. Rebstock was incorrectly affiliated with 'Falklands Conservation, Stanley, FIQQ1ZZ, Falkland Islands'. The correct affiliation is listed below.

Center for Ecosystem Sentinels, Department of Biology, University of Washington, Seattle, WA, USA.

Additionally, in the original article affiliations 15, 18 and 19 were not listed in the correct order. The correct affiliations are listed below:

Affiliation 15:

CESAM, Departamento de Biologia Animal, Faculdade de Ciências, Universidade de Lisboa, Portugal.

Affiliation 18:

Wildlife Research Division, Science and Technology Branch, Environment and Climate Change Canada, Mount Pearl, NL, A1N 4T3, Canada.

Affiliation 19:

Department of Animal Ecology \& Systematics, Justus Liebig University, Giessen, Germany.

The original version of this Article also contained errors in Affiliation 20, which was incorrectly given as 'Psycholgy Department, Memorial University of Newfoundland, St John's, Canada'. The correct affiliation is listed below:

Psychology Department, Memorial University of Newfoundland, St John's, NL, A1C 3C9, Canada.

Lastly, the original version of this Article contained a typographical error in the Abstract. 
"Despite the important role marine predators play in structuring the ecosystems, areas of high diversity where multiple predators congregate remains poorly known on the Patagonian Shelf."

now reads:

"Despite the important role marine predators play in structuring ecosystems, areas of high diversity where multiple predators congregate remains poorly known on the Patagonian Shelf."

These errors have now been corrected in the PDF and HTML versions of the Article and in the accompanying Supplementary Materials file.

(c) (i) Open Access This article is licensed under a Creative Commons Attribution 4.0 International License, which permits use, sharing, adaptation, distribution and reproduction in any medium or format, as long as you give appropriate credit to the original author(s) and the source, provide a link to the Creative Commons license, and indicate if changes were made. The images or other third party material in this article are included in the article's Creative Commons license, unless indicated otherwise in a credit line to the material. If material is not included in the article's Creative Commons license and your intended use is not permitted by statutory regulation or exceeds the permitted use, you will need to obtain permission directly from the copyright holder. To view a copy of this license, visit http://creativecommons.org/licenses/by/4.0/.

(C) The Author(s) 2019 